\title{
Human genetics of diabetic cardiovascular complications
}

\begin{abstract}
Diabetic cardiovascular complications (DCC) affecting the important organ systems of human body - cardiovascular system contributes a major public health problem. There is evidence demonstrating that genetic factors contribute to the risk of DCC. Genetics variants, structural variants play important roles in the development of DCC. In addition, mitochondrial DNA plays critical roles in regulation of development of DCC. This review focused on the current knowledge of the genetic basis of DCC. Ultimately, identification of genes or genetic loci, and structural variants associated with DCC will be for the benefit of the development of personalized medicine in diabetes mellitus and it complications.
\end{abstract}

Keywords: diabetic cardiovascular complications, genetics, mitochondrial DNA, interactions of gene by environment
Volume I Issue 3 - 2014

\author{
Min-Dan Xu, Lin Wang, Zi-Hui Tang, Keqin \\ Zhang \\ Department of Endocrinology and Metabolism, Tongii University,
} China

Correspondence: Zi Hui Tang, Department of Endocrinology and Metabolism, Shanghai Tongii Hospital, Tongii University, Building 5\#, NO. 389 Xincun Road, Shanghai, 200065, China, Tel 008615821993541 , Fax 008602166111061 ,

Email albert.tang@163.com

Ke-Qin Zhang, Department of Endocrinology and Metabolism, Shanghai Tongii Hospital, Tongji University, Building 5\#, NO. 389 Xincun Road, Shanghai, 200065, China, Fax 008602 I 66II I06I, Email dr.zhoulinuo@gmail.com

Received: June 02, 2014 | Published: July 22, 2014
Abbreviations: DCC, diabetic cardiovascular complications; mtDNA, mitochondrial DNA; SSRs, simple sequence repeats; STRs, short tandem repeats; CPI, combined paternity index; LOD, logarithm of odds; SNPs, single nucleotide polymorphisms; GWAS, genome-wide association studies; HDL, high density lipoprotein; MI, myocardial infarction; CAD, coronary artery disease; $\mathrm{Lp}$, lipoprotein; $\mathrm{CNV}$, copy number variation; T2DM, type 2 diabetes mellitus; CKD, chronic kidney disease

\section{Introduction}

The diabetic cardiovascular complications (DCC) involve the cardiovascular system, and are often classified as macro-vascular complications. ${ }^{1-3}$ A large body of evidence indicates that major risk factors, such as long-term diabetes, poor control of blood glucose, and elevated blood pressure are responsible for the onset and progression of diabetic complications. ${ }^{4}$ Patients cannot be stratified with respect to their risk of developing DCC based only upon clinical or procedural risk factors. A large body of evidence for the role of genetic factors in DCC has been generated over several decades. Genetic studies have reported that DCC has $40 \%-50 \%$ of the variance within indices for the extent of atherosclerosis, i.e. coronary calcium and carotid intimamedia thickness, can be attributed to familial factors among subjects with diabetes. ${ }^{5,6}$ DCC can be considered as a classic example of a human complex disease attributed to genetic factors, environmental factors and interactions between them.

Currently, multiple genetic approaches have been used to identify which genetic loci or genes are risk factors for developing this complex disease. Genetic linkage analyses have been performed under the 'rare variant' hypothesis to identify genetic loci using extended families or sibling pairs. Genetic association analyses under the 'common variant' hypothesis have identified genetic susceptibility variants via a dense marker map. ${ }^{7}$ Genetic analysis of mitochondrial DNA (mtDNA), including mtDNA genome association analysis and copy number analysis have provided insights into the underlying mechanisms of DCC.

This review focuses on the current knowledge of the genetic and epigenetic basis of DCC and summarizes data from previous genetic studies regarding susceptibility genetic variants that influence DCC. Ultimately, the identification of genetic variants and structural variants will be of benefit to the development of personalized medicine in DCC.

\section{Genetic Linkage Analysis}

Genetic linkage analysis detects the chromosomal location of disease genes and is based on the observation that genes that are physically close together on a chromosome remain linked during meiosis. ${ }^{9}{ }^{10}$ For this approach to be successful, it is very important to define a specific phenotype associated with each gene. Two classical approaches, parametric tests and non-parametric tests, are commonly used in genetic linkage analyses. ${ }^{11-14}$ It is also critical to choose proper genetic markers for genetic linkage analysis. Microsatellites, also known as simple sequence repeats (SSRs) or short tandem repeats (STRs), are repeating sequences of 2-5 base pairs of DNA. This genetic marker is used as molecular markers in STR analysis, for kinship, population and other studies and used for studies of gene duplication or deletion, marker assisted selection and fingerprinting. Furthermore, the markers are most widely used owing to microsatellite loci being linked to highly polymorphic regions with greater than the combined paternity index (CPI). ${ }^{15}$ The LOD score (logarithm (base 10) of odds), is a statistical test often used for linkage analysis in human, animal, and plant populations. The LOD score compares the likelihood of obtaining the test data if the two loci are indeed linked, to the likelihood of observing the same data purely by chance. Positive LOD scores favor the presence of linkage, whereas negative LOD scores indicate that linkage is less likely. 
For candidate gene analysis, candidate genes of known sequence and location are identified that may be involved in disease pathogenesis and these are often selected on the basis of their physiological functions. In contrast, genome-wide screens are a more powerful approach that can be used to screen the whole human genome for gene linkage or association with a disease without making any assumptions regarding disease pathogenesis. ${ }^{16,17}$ This type of approach been used successfully to identify susceptibility genetic loci for DCC. Genetic linkage analysis often consists of the following steps: identifying linked loci, confirming linked loci, fine mapping of confirmed loci and then testing genes in the linked region in functional studies. ${ }^{18}$

Two whole genome linage analysis for DCC have been conducted to detected several chromosome regions such as $19 \mathrm{q}, 3 \mathrm{p}$ and $11 \mathrm{p}$ with linkage evidence to the complications. ${ }^{19,20}$ Elbein et al. ${ }^{19}$ have performed genome wide linkage study for DCC in Caucasian to detect 19 q 13.2 with the strongest linkage evidence. Chromosomes $3 p, 11 p$ and $19 p-q$ have been identified with linkage evidence to DCC in a whole genome scan study in Caucasian, Hispanic and AfricanAmerican, respectively. ${ }^{20}$ Interestingly, although the two genome wide linkage studies have been conducted in different ethnicity, linkage evidence to chromosome $19 \mathrm{q}$ has been consistently detected (Table 1).

Table I Genetic linkage analysis for diabetic cardiovascular complications

\begin{tabular}{lll}
\hline Chromosome region & Population studied & Reference \\
\hline$|9 q| 3.2$ & Caucasian & 19 \\
$3 p|2|-.3 q|3.3|$ & Caucasian & 20 \\
||$p|5.4-||p| \mid .3$ & Hispanic & 20 \\
$|9 p| 3.2-|9 q| 3.42$ & African-American & 20
\end{tabular}

\section{Genetic Association Analysis}

Genetic association studies are more sensitive and may detect minor susceptibility genes contributing less than $5 \%$ of the total genetic contribution to a disease. ${ }^{7,9}$ The approach used for this type of analysis is based on comparing the frequency of the allele studied in unrelated patients with matched controls. If the allele appears significantly more frequently in patients than in controls, then it is considered to be associated with the disease. ${ }^{21}$ Single nucleotide polymorphisms (SNPs) are the most important genetic markers for genetic association analysis, due to the abundance of SNPs covering the entire human genome at a high density. ${ }^{22-24}$ Candidate gene association analyses use candidate genes of a known sequence and location that are considered to be involved in the disease pathology. However, approaches based on prior hypothesis have a limited power to detect novel genetic variants. Instead, a non-prior hypothesis is a more powerful approach for identifying gene(s) association with a disease by screening the whole human genome. Genome-wide association studies (GWAS) became a reality following the publication of the HapMap of the human genome..$^{25}$ Recently, several genes associated with type 2 diabetes have been reproducibly identified using genome-wide association studies. ${ }^{26}$ Genetic association-based gene mapping consists of the following steps: genome-wide association using tag SNPs, confirming SNP association, gene identification and then functional studies.

Many candidate association studies have been performed to identify genes linked to cardiovascular disease (CVD) and/or diabetes mellitus and some gene associations have been consistently reported. ${ }^{27}$ For example, polymorphisms in genes related to lipid metabolism or fibrinolysis, including $A P O E, A P O B, A P O C, P O N, C E T P$, and PAII, have been shown to increase the risk of ischemic vascular disease in diabetic patients. It is well known that lipid factors and their oxidation influence the development of diabetic metabolic syndrome and CVD. Further, $A P O E, A P O B$, or $A P O C$ gene polymorphisms have been reported to associate with macrovascular complications of diabetes, ${ }^{28,29}$ although these results have yet to be reproduced. Paraoxonase is an enzyme associated with high density lipoprotein (HDL) and $P O N$ is considered as a candidate gene for DCC. Interestingly, an association between polymorphisms in this gene and the risk of CVD has been consistently described in patients with T2DM from different ethnic backgrounds $^{30-34}$ and three polymorphisms (rs662, rs854560 and Q191R have been linked with the risk of CVD in patients with T2DM. ${ }^{35-37}$ Patients with diabetes carrying the G allele of the rs662 polymorphism have been found to have more than double the risk of myocardial infarction (MI) than patients with other alleles. ${ }^{35}$ The exonic rs 854560 polymorphism causes a leucine to methionine change in the encoded protein and strongly influences gene expression and serum levels of the enzyme. ${ }^{36}$ Furthermore, the Q191R polymorphism was previously identified as an independent risk factor for CVD in patients with diabetes. ${ }^{37}$ There is now a large body of evidence implicating this polymorphism as a genetic determinant for the risk of ischemic vascular disease in T2DM. CETP plays a key role in the metabolism of HDL, which regulates uptake of cholesterol by hepatocytes, and CETP polymorphism is a strong and independent risk factor for atherosclerotic vascular disease. Interestingly, the CETP rs1800774 polymorphism has been reported to associate with macrovascular disease in male T2DM patients independently of lipid levels. ${ }^{38-42}$ It is well known that PAI-1 is the main circulating inhibitor of fibrinolysis, which causes thrombus dissolution. A single base insertion/deletion polymorphism of rs1799889 in the promoter of the PAIl gene can partially determine the levels of PAI- $1^{43}$ and a possible association between this polymorphism and the risk of CVD in patients with T2DM has been reviewed in a meta-analysis. ${ }^{44}$ An interaction of $A C E$ genotype with the PAII genotype has also been reported. ${ }^{45}$ In addition, two studies show apparently contradictory results regarding the rs2227631 ( $-455 \mathrm{G} / \mathrm{A})$ polymorphism of the fibrinogen gene. In one study, this allele was found to be associated with higher levels of fibrinogen and an increased risk of coronary disease in Chinese diabetic patients. ${ }^{46}$ However, a second study conducted in an English T2DM population suggested that the $\mathrm{G}$ allele was associated with an increased risk of coronary artery disease (CAD), without affecting circulating fibrinogen levels. ${ }^{47}$

No published reports have been found to GWAS for CAD being performed in the diabetic population specifically. However, findings from several GWAS for CAD conducted in the general population showed a potential relation to diabetic subjects. ${ }^{48,49}$ Twelve loci with genome-wide significance have been found to associate with either $\mathrm{CAD}$ or $\mathrm{MI}$ in the general population. Two of 12 genes - LDLR and PCSK 9 are mutated in Mendelian forms of hypercholesterolemia, ${ }^{50}$ as are genes in the SLC22A3-LPAL2-LPA cluster, which includes the gene for the atherogenic lipoprotein (Lp) (a). Moreover, variations at chromosome 9p21 have been found to significantly associate with CVD in the general population. ${ }^{51,52}$ In addition, the locus has a larger effect on CVD risk among patients with T2DM. ${ }^{53}$ In general, common genetic variants with small effects do not significantly improve predictive algorithms for other complex disorders; however, the chromosome 9p21 locus indicates some genes associated with CVD. ${ }^{54}$ For example, haplotype analyses have found an interesting CVD association with a group of SNPs residing in a $60 \mathrm{~kb}$ region 
that includes ANRIL. ${ }^{55-56} \mathrm{~A}$ decreased risk associated with the long to short variant ratio has been reported for this allele. ${ }^{57,58} A N R I L$ links to the $C D K N 2 A$ and $C D K N 2 B$ genes, which are involved in the control cell the control cell proliferation, cell aging and apoptosis. ${ }^{59,60}$ Hyperglycemia and variation in the 9p21 locus may induce vascular smooth muscle cell proliferation. ${ }^{61}$ It is thought that several others of the 12genes identified in the general population can also influence the risk of CAD in the diabetic population. ${ }^{62}$ In addition, the chromosome 6p24 locus, which includes the PHACTR1 gene, has been found to promote CAD with a strong effect, second only to that of the $9 \mathrm{p} 21$ locus. ${ }^{63}$ Interestingly, $R A G E$ gene has been found to associate with both DN and DR, $A G E$ gene associate with both DN and DCC, and $V E G F$ gene associate with DR and DCC. Unfortunately, no shared gene has been found to associate with the three complications (Table 2).

Table 2 Genetic association analysis for diabetic cardiovascular complications

\begin{tabular}{|c|c|c|}
\hline Polymorphism & Candidate gene & Reference \\
\hline rs2383206 & $9 p 21$ & $\begin{array}{l}4 \\
\text { McPherson et al., 2007) }\end{array}$ \\
\hline Insertion/deletion & ACE & 5,7 \\
\hline rs2232853 & ADIPORI & 6 \\
\hline rs 12733285 & ADIPORI & 6 \\
\hline rs 1342387 & ADIPORI & 6 \\
\hline rs7539542 & ADIPORI & 6 \\
\hline rsl0920531 & ADIPORI & 6 \\
\hline rs4950894 & ADIPORI & 6 \\
\hline rs5186 & AGTRI & 7 \\
\hline rs 1535045 & $C D 40$ & 13 \\
\hline rs3765459 & CD40 & 13 \\
\hline rs3092948 & CD40L & 13 \\
\hline rs3092929 & CD40L & 13 \\
\hline rs3092923 & CD40L & 13 \\
\hline rs3092920 & CD40L & 13 \\
\hline rs2897|4 & CETP & 14 \\
\hline rs689466 & $\operatorname{cox} 2$ & 15 \\
\hline rs20417 & $\operatorname{cox} 2$ & 15 \\
\hline rs2745557 & $\operatorname{cox} 2$ & 15 \\
\hline rs5277 & $\operatorname{cox} 2$ & 15 \\
\hline rs20432 & $\operatorname{cox} 2$ & 15 \\
\hline rs2066826 & $\operatorname{cox} 2$ & 15 \\
\hline rs5275 & $\operatorname{cox} 2$ & 15 \\
\hline rs10911902 & $\operatorname{cox} 2$ & 15 \\
\hline rs7003694 & $E P H X 2$ & 18 \\
\hline rs7837347 & $E P H X 2$ & 18 \\
\hline R287Q & $E P H X 2$ & 18 \\
\hline rs 721619 & EPHX2 & 18 \\
\hline
\end{tabular}

Table Continued...

\begin{tabular}{lll}
\hline Polymorphism & Candidate gene & Reference \\
\hline rs747276 & EPHX2 & 18 \\
rs285 & LPL & 14 \\
rs320 & LPL & 14 \\
rsI800566 & NQOI & 21 \\
insertion/deletion & PAI-I & 22 \\
rs2904268 & PTPNI & 26 \\
rs803742 & PTPNI & 26 \\
rsI967439 & PTPNI & 26 \\
rs7I8630 & PTPNI & 26 \\
rs48II078 & PTPNI & 26 \\
rs2206656 & PTPNI & 26 \\
rs932420 & PTPNI & 26 \\
rs3787335 & PTPNI & 26 \\
rs2426I58 & PTPNI & 26 \\
rs2904269 & PTPNI & 26 \\
rs94I798 & PTPNI & 26 \\
rsI570I79 & PTPNI & 26 \\
rs3787345 & PTPNI & 26 \\
Insertion/Deletion & VEGF & 93 \\
\hline
\end{tabular}

\section{mtDNA association analysis}

mtDNA is non-genomic DNA located within mitochondria, which are the structures within eukaryotic cells that convert the chemical energy from food into ATP. The mitochondrial genome is highly compact, consisting of double-stranded circular mtDNA greater than $16 \mathrm{~kb}$ in length. In humans, each cell contains between several hundred and more than a thousand mitochondria and each mitochondrion contains $2-10$ copies of mtDNA. The number of mitochondria and mtDNA copies can vary dramatically in response to energy demand and under different physiological conditions and are tightly controlled by mitochondrial biogenesis. The consequence of mtDNA mutation may be a change in the protein-coding sequence, which may affect organism metabolism. Alterations in mitochondrial biogenesis may be the underlying pathological factors for several human complex diseases such as diabetes mellitus or DCC. ${ }^{64-66}$ Further, there is compelling evidence for a genetic predisposition to diabetes complications $^{67-73}$ Single mtDNA mutations and mitochondrial haplogroups are associated with T2DM and many studies have evaluated mtDNA variation in T2DM patients. These subjects also showed a slight decrease in HDL cholesterol, indicating that the entire haplogroup $\mathrm{H}$ might play an important role in diabetic cardiovascular complications. This compelling analysis of grouped complications provides some initial clues concerning the role of mitochondrial haplogroups in modulating the course of the diabetes mellitus.

\section{Copy number variant analysis}

Recent discoveries have revealed that large segments of DNA can vary in copy number between individuals. A copy number variation $(\mathrm{CNV})$ is a segment of DNA in which copy number differences have been found in two or more genomes; the segment may range from 
one kilobase to several megabases in size ${ }^{74} \mathrm{CNVs}$ can encompass genes, leading to dosage imbalances, and this may play important role both in human disease and in drug response. It was first realized that DNA, CNV is a widespread and common phenomenon among humans after the completion of the human genome project. ${ }^{75,76} \mathrm{CNVs}$ can lead to variations in dosage sensitive genes, which may contribute to a substantial amount of human phenotypic variability and disease susceptibility. ${ }^{77,78}$ In genome-wide association studies, the raw intensity data generated from SNP genotyping can be mined for copy number information. ${ }^{79,80}$ Unfortunately, no published genetic study to date has performed copy number variation analysis to identify associations between CNVs and DCC.

\section{Gene-environment interaction analysis}

Current genetic association analyses are designed to detect strong and direct associations of a SNP or clusters of SNPs, with disease. ${ }^{81,82}$ However, in the context of complex diseases, scanning for strong associations may miss important genetic variants specific to subpopulations, defined by their exposure to particular environmental factors. Interactions of functional gene polymorphisms with environmental factors play a substantial role in disease risk. ${ }^{83}$ Thus, in a genome-wide association study, gene-environment interactions are worth further investigation ${ }^{84}$ First, gene-environment interactions can reveal fundamental biological mechanisms and the effects of individual components on a complex mixture and can be important for risk prediction and for evaluating the benefit of changes in modifiable environmental factors. ${ }^{85-87}$ Gene-environment studies have been performed for exposure-related diseases such as asthma, lung cancer and T2DM. ${ }^{88,89}$ Unfortunately, no published study to date has performed a gene-environment interaction analysis to identify interactions for DCC.

\section{Conclusion}

With the development of GWAS, many genetic polymorphisms with a possible impact on DCC have been identified. However, it has been reported to inconsistent identifications of the genetic variants underlying susceptibility to DCC from GWAS. Standardization of phenotypes and genotyping protocols has been considered essential for GWAS due to the methods could pooling of individual patient level data in meta-analyses to increase their power. For cardiovascular complications, $9 \mathrm{p} 21$ has been found association with coronary artery disease and diabetes mellitus, respectively, which suggests that potential shared candidate gene associated with both diseases. The successful identification of the disease at an early stage, leading to changes in lifestyle and dietary behavior, is important for prevention and control of the disease. It is expected that characterization of the genetic factors involved in the development of diabetes mellitus and its complications will lead to the understanding of the molecular pathogenesis and the development of novel therapeutic approaches. Although there are many differences between mtDNA and nuclear DNA, there is coordinated expression and interaction between the gene products of the mitochondria and nuclear genomes.

Because DCC is involved in the important systems of human the cardiovascular system in a diabetic background, we can consider that shared genes influence the development of both systems and of diabetes mellitus. Thus, based on data from genome-wide scans for DCC, we can perform multivariant genome-wide association analysis for these systems and for diabetes mellitus. We have performed bivariate genome-wide linkage analyses for obesity and osteoporosis $^{90}$ and found several novel chromosomal regions that may influence both. We also plan to perform multivariant genomewide association analysis for chronic kidney disease (CKD) and T2DM, and for CVD and T2DM. Recently, pathway-based genomewide association analyses have been conducted to identify pathways underlying complex human disease, based on data from genome-wide scans. Similar analyses should reveal pathway-based genome-wide associations for DCC.

Whole genome sequencing study with "next generation sequencing" technology is an efficient strategy to sequence the human genome in order to identify novel genes associated with rare and common disorders. ${ }^{91}$ Whole genome sequencing will eventually become a standard approach and allow us to gain a deeper understanding of genetic variation found in populations ${ }^{92}$ Presently, this technique is not practical owing to the high costs and time associated with sequencing large numbers of genomes. Such technology can be considered to open a new window for genetic research of DCC. Further, new genetic analysis approaches based on next generation sequencing technology combined with gene-environment interaction and pathway-based approach analyses provide a powerful tool to explore the genetic mechanisms involved in the development of DCC. ${ }^{93}$

\section{Acknowledgments}

We thank the grant from China National Grant on Science and Technology to support the study.

\section{Conflict of interest}

Author declares that there is no conflict of interest.

\section{References}

1. Rema M, Premkumar S, Anitha B, et al. Prevalence of diabetic retinopathy in urban India: the Chennai Urban Rural Epidemiology Study (CURES) eye study, I. Invest Ophthalmol Vis Sci. 2005;46(7):2328-2333.

2. Wild S, Roglic G, Green A, et al. Global prevalence of diabetes: estimates for the year 2000 and projections for 2030. Diabetes Care. 2004;27(5):1047-1053.

3. Jones CA, Krolewski AS, Rogus J, et al. Epidemic of end-stage renal disease in people with diabetes in the United States population: do we know the cause? Kidney Int. 2005;67(5):1684-1691.

4. Hoerger TJ, Segel JE, Gregg EW, et al. Is glycemic control improving in U.S. adults? Diabetes Care. 2008;31(1):81-86.

5. Lange LA, Bowden DW, Langefeld CD, et al. Heritability of carotid artery intima-medial thickness in type 2 diabetes. Stroke. 2002;33(7):1876-1881.

6. Wagenknecht LE, Bowden DW, Carr JJ, et al. Familial aggregation of coronary artery calcium in families with type 2 diabetes. Diabetes. 2001;50(4):861-866

7. Risch N, Merikangas K. The future of genetic studies of complex human diseases. Science. 1996;273(5281):1516-1517.

8. Lowell BB, Shulman GI. Mitochondrial dysfunction and type 2 diabetes. Science. 2005;307(5708):384-387.

9. Greenberg DA. Linkage analysis of "necessary" disease loci versus "susceptibility” loci. Am J Hum Genet. 1993;52(1):135-143.

10. Remmers EF, Griffiths MM, Longman RE, et al. An integrated rat genetic map: analysis of linkage conservation with the mouse and human maps. Transplant Proc. 1999;31(3):1549-1554. 
11. Greenberg DA, Abreu PC. Determining trait locus position from multipoint analysis: accuracy and power of three different statistics. Genet Epidemiol. 2001;21(4):299-314.

12. Terwilliger JD, Zollner S, Laan M, et al. Mapping genes through the use of linkage disequilibrium generated by genetic drift: 'drift mapping' in small populations with no demographic expansion. Hum Hered. 1998;48(3):138-154

13. Hodge SE, Anderson CE, Neiswanger $\mathrm{K}$, et al. The search for heterogeneity in insulin-dependent diabetes mellitus (IDDM): linkage studies, two-locus models, and genetic heterogeneity. Am J Hum Genet 1983;35(6):1139-1155.

14. Risch N. Linkage strategies for genetically complex traits. II. The power of affected relative pairs. Am J Hum Genet. 1990;46(2):229-241.

15. Weber JL. Human DNA polymorphisms and methods of analysis. Curr Opin Biotechnol. 1990;1(2):166-171.

16. Davies JL, Kawaguchi Y, Bennett ST, et al. A genome-wide search for human type 1 diabetes susceptibility genes. Nature. 1994;371(6493):130-136.

17. Hunter DJ, Kraft P. Drinking from the fire hose--statistical issues in genomewide association studies. N Engl J Med. 2007;357(5):436-439.

18. Glazier AM, Nadeau JH, Aitman TJ. Finding genes that underlie complex traits. Science. 2002;298(5602):2345-2349.

19. Elbein SC, Hasstedt SJ. Quantitative trait linkage analysis of lipid-related traits in familial type 2 diabetes: evidence for linkage of triglyceride levels to chromosome 19q. Diabetes. 2002;51(2):528-535.

20. Malhotra A, Wolford JK. Analysis of quantitative lipid traits in the genetics of NIDDM (GENNID) study. Diabetes. 2005;54(10):3007-3014.

21. Hodge SE. What association analysis can and cannot tell us about the genetics of complex disease. Am J Med Genet. 1994;54(4):318-323.

22. Brookes AJ. The essence of SNPs. Gene. 1999;234(2):177-186.

23. Laan M, Paabo S. Mapping genes by drift-generated linkage disequilibrium. Am J Hum Genet. 1998;63(2):654-656.

24. Ogura $\mathrm{Y}$, Bonen DK, Inohara $\mathrm{N}$, et al. A frameshift mutation in NOD2 associated with susceptibility to Crohn's disease. Nature. 2001;411(6837):603-606.

25. International HapMap Consortium. A haplotype map of the human genome. Nature. 2005;437(7063):1299-1320.

26. Frayling TM. Genome-wide association studies provide new insights into type 2 diabetes aetiology. Nat Rev Genet. 2007;8(9):657-662.

27. Iacoviello L, Donati MB. Blood coagulation factor VII activity and the risk of myocardial infarction: the novel identification of a genetic protection that can be mimicked by an old drug. G Ital Cardiol. 1998;28(6):718-721

28. Semenkovich CF, Heinecke JW. The mystery of diabetes and atherosclerosis: time for a new plot. Diabetes. 1997;46(3):327-334.

29. Barakat K, Hitman GA. Genetic susceptibility to macrovascular complications of type 2 diabetes mellitus. Best Pract Res Clin Endocrinol Metab. 2001;15(3):359-370.

30. Ruiz J, Blanche H, James RW, et al. Gln-Arg192 polymorphism of paraoxonase and coronary heart disease in type 2 diabetes. Lancet. 1995;346(8979):869-872.

31. Sakai T, Matsuura B, Onji M. Serum paraoxonase activity and genotype distribution in Japanese patients with diabetes mellitus. Intern Med. 1998;37(7):581-584
32. Odawara M, Tachi Y, Yamashita K. Paraoxonase polymorphism (Gln192-Arg) is associated with coronary heart disease in Japanese noninsulin-dependent diabetes mellitus. $J$ Clin Endocrinol Metab. 1997;82(7):2257-2260

33. Osei-Hyiaman D, Hou L, Mengbai F, et al. Coronary artery disease risk in Chinese type 2 diabetics: is there a role for paraxonase 1 gene (Q192R) polymorphism? Eur J Endocrinol. 2001;144(6):639-644.

34. Pfohl M, Koch M, Enderle MD, et al. Paraoxonase 192 Gln/Arg gene polymorphism, coronary artery disease, and myocardial infarction in type 2 diabetes. Diabetes. 1999;48(3):623-627.

35. Aubo C, Senti M, Marrugat J, et al. Risk of myocardial infarction associated with Gln/Arg 192 polymorphism in the human paraoxonase gene and diabetes mellitus. The REGICOR Investigators. Eur Heart J. 2000;21(1):33-38.

36. Leviev I, Negro F, James RW. Two alleles of the human paraoxonase gene produce different amounts of mRNA. An explanation for differences in serum concentrations of paraoxonase associated with the (Leu-Met54) polymorphism. Arterioscler Thromb Vasc Biol. 1997;17(11):2935-2939.

37. James RW, Leviev I, Ruiz J, et al. Promoter polymorphism T(-107)C of the paraoxonase PON1 gene is a risk factor for coronary heart disease in type 2 diabetic patients. Diabetes. 2000;49(8):1390-1393.

38. Ukkola O, Savolainen MJ, Salmela PI, et al. DNA polymorphisms at the lipoprotein lipase gene are associated with macroangiopathy in type 2 (non-insulin-dependent) diabetes mellitus. Atherosclerosis. 1995;115(1):99-105.

39. Ukkola O, Savolainen MJ, Salmela PI, et al. DNA polymorphisms at the locus for human cholesteryl ester transfer protein (CETP) are associated with macro- and microangiopathy in non-insulin-dependent diabetes mellitus. Clin Genet. 1994;46(3):217-227.

40. Durlach A, Clavel C, Girard-Globa A, et al. Sex-dependent association of a genetic polymorphism of cholesteryl ester transfer protein with highdensity lipoprotein cholesterol and macrovascular pathology in type II diabetic patients. J Clin Endocrinol Metab. 1999;84(10):3656-3659.

41. Kawasaki I, Tahara H, Emoto M, et al. Relationship between TaqIB cholesteryl ester transfer protein gene polymorphism and macrovascular complications in Japanese patients with type 2 diabetes. Diabetes. 2002;51(3):871-874

42. Meguro S, Takei I, Murata M, et al. Cholesteryl ester transfer protein polymorphism associated with macroangiopathy in Japanese patients with type 2 diabetes. Atherosclerosis. 2001;156(1):151-156.

43. Mansfield MW, Stickland MH, GrantPJ. Plasminogen activator inhibitor-1 (PAI-1) promoter polymorphism and coronary artery disease in noninsulin-dependent diabetes. Thromb Haemost. 1995;74(4):1032-1034.

44. Iacoviello L, Burzotta F, Di Castelnuovo A, et al. The 4G/5G polymorphism of PAI-1 promoter gene and the risk of myocardia infarction: a meta-analysis. Thromb Haemost. 1998;80(6):1029-1030.

45. Kimura H, Gejyo F, Suzuki Y, et al. Polymorphisms of angiotensin converting enzyme and plasminogen activator inhibitor-1 genes in diabetes and macroangiopathy1. Kidney Int. 1998;54(5):1659-1669.

46. Lam KS, Ma OC, Wat NM, et al. Beta-fibrinogen gene G/A-455 polymorphism in relation to fibrinogen concentrations and ischaemic heart disease in Chinese patients with type II diabetes. Diabetologia. 1999;42(10):1250-1253.

47. Carter AM, Mansfield MW, Stickland MH, et al. Beta-fibrinogen gene-455 G/A polymorphism and fibrinogen levels. Risk factors for coronary artery disease in subjects with NIDDM. Diabetes Care. 1996;19(11):1265-1268 
48. Erdmann J, Grosshennig A, Braund PS, et al. New susceptibility locus for coronary artery disease on chromosome 3q22.3. Nat Genet. 2009;41(3):280-282

49. Wellcome Trust Case Control Consortium. Genome-wide association study of 14,000 cases of seven common diseases and 3,000 shared controls. Nature. 2007;447(7145):661-678

50. Abifadel M, Varret M, Rabes JP, et al. Mutations in PCSK9 cause autosomal dominant hypercholesterolemia. Nat Genet. 2003;34(2):154-156.

51. Helgadottir A, Thorleifsson G, Manolescu A, et al. A common variant on chromosome 9p21 affects the risk of myocardial infarction. Science. 2007;316(5830):1491-1493.

52. McPherson R, Pertsemlidis A, Kavaslar N, et al. A common allele on chromosome 9 associated with coronary heart disease. Science. 2007;316(5830):1488-1491

53. Doria A, Wojcik J, Xu R, et al. Interaction between poor glycemic control and $9 \mathrm{p} 21$ locus on risk of coronary artery disease in type 2 diabetes. JAMA. 2008;300(20):2389-2397.

54. Meiqs JB, Shrader P, Sullivan LM, et al. Genotype score in addition to common risk factors for prediction of type 2 diabetes. $N$ Engl J Med. 2008;359(21):2208-2219.

55. Samani NJ, Erdmann J, Hall AS, et al. Genomewide association analysis of coronary artery disease. $N$ Engl J Med. 2007;357(5):443-453.

56. Broadbent HM, Peden JF, Lorkowski S, et al. Susceptibility to coronary artery disease and diabetes is encoded by distinct, tightly linked SNPs in the ANRIL locus on chromosome 9p. Hum Mol Genet. 2008;17(6):806-814

57. Jarinova O, Stewart AF, Roberts R, et al. Functional analysis of the chromosome 9p21.3 coronary artery disease risk locus. Arterioscler Thromb Vasc Biol. 2009;29(10):1671-1677.

58. Kathiresan S, Voight BF, Purcell S, Musunuru K, Ardissino D, et al. (2009) Genome-wide association of early-onset myocardial infarction with single nucleotide polymorphisms and copy number variants. Nat Genet. 2009;41(3):334-341.

59. Kamb A, Gruis NA, Weaver-Feldhaus J, et al. A cell cycle regulato potentially involved in genesis of many tumor types. Science. 1994;264(5157):436-440.

60. Visel A, Zhu Y, May D, et al. Targeted deletion of the 9p21 noncoding coronary artery disease risk interval in mice. Nature. 2010;464(7287):409-412.

61. Natarajan R, Gonzales N, Xu L, et al. Vascular smooth muscle cells exhibit increased growth in response to elevated glucose. Biochem Biophys Res Commun. 1992;187(1):552-560

62. Cheng X, Shi L, Nie S, et al. The same chromosome 9p21.3 locus is associated with type 2 diabetes and coronary artery disease in a Chinese Han population. Diabetes. 2011;60(2):680-684.

63. Novelli G, Predazzi IM, Mango R, et al. Role of genomics in cardiovascular medicine. World J Cardiol. 2010;2(12):428-436.

64. Aliev G, Smith MA, Obrenovich ME, et al. Role of vascular hypoperfusion-induced oxidative stress and mitochondria failure in the pathogenesis of Azheimer disease. Neurotox Res. 2003;5(7):491-504.

65. Hagiwara M, Yamagata K, Capaldi RA, et al. Mitochondrial dysfunction in focal segmental glomerulosclerosis of puromycin aminonucleoside nephrosis. Kidney Int. 2006;69(7):1146-1152.

66. Ceriello A, Ihnat MA, Thorpe JE. Clinical review 2: The "metabolic memory": is more than just tight glucose control necessary to preven diabetic complications? J Clin Endocrinol Metab. 2009;94(2):410-415.
67. Newman B, Selby JV, King MC, et al. Concordance for type 2 (noninsulin-dependent) diabetes mellitus in male twins. Diabetologia. 1987;30(10):763-768.

68. Kaprio J, Tuomilehto J, Koskenvuo M, et al. Concordance for type 1 (insulin-dependent) and type 2 (non-insulin-dependent) diabetes mellitus in a population-based cohort of twins in Finland. Diabetologia. 1992;35(11):1060-1067.

69. Medici F, Hawa M, Ianari A, et al. Concordance rate for type II diabetes mellitus in monozygotic twins: actuarial analysis. Diabetologia. 1999;42(2):146-150.

70. Ballinger SW, Shoffner JM, Hedaya EV, et al. Maternally transmitted diabetes and deafness associated with a $10.4 \mathrm{~kb}$ mitochondrial DNA deletion. Nat Genet. 1992;1(1):11-15.

71. Rotig A, Bessis JL, Romero N, et al. Maternally inherited duplication of the mitochondrial genome in a syndrome of proximal tubulopathy, diabetes mellitus, and cerebellar ataxia. Am J Hum Genet. 1992;50(2):364-370.

72. Rosen P, Nawroth PP, King G, et al. The role of oxidative stress in the onset and progression of diabetes and its complications: a summary of a Congress Series sponsored by UNESCO-MCBN, the American Diabetes Association and the German Diabetes Society. Diabetes Metab Res Rev. 2001;17(3):189-212.

73. Brownlee M. Biochemistry and molecular cell biology of diabetic complications. Nature. 2001;414(6865):813-820.

74. Cook EH, Scherer SW. Copy-number variations associated with neuropsychiatric conditions. Nature. 2008;455(7215):919-923.

75. Sebat J, Lakshmi B, Troge J, et al. Large-scale copy number polymorphism in the human genome. Science. 2004;305(5683):525-528.

76. Iafrate AJ, Feuk L, Rivera MN, et al. Detection of large-scale variation in the human genome. Nat Genet. 2004;36(9):949-951.

77. Redon R, Ishikawa S, Fitch KR, et al. Global variation in copy number in the human genome. Nature. 2006;444(7118):444-454.

78. Freeman JL, Perry GH, Feuk L, et al. Copy number variation: new insights in genome diversity. Genome Res. 2006;16(8):949-961.

79. Lieberfarb ME, Lin $M$, Lechpammer $M$, et al. Genome-wide loss of heterozygosity analysis from laser capture microdissected prostate cancer using single nucleotide polymorphic allele (SNP) arrays and a novel bioinformatics platform dChipSNP. Cancer Res. 2003;63(16):4781-4785.

80. Zhao X, Weir BA, LaFramboise $\mathrm{T}$, et al. Homozygous deletions and chromosome amplifications in human lung carcinomas revealed by single nucleotide polymorphism array analysis. Cancer Res. 2005;65(13):5561-5570.

81. Browning BL, Browning SR. Efficient multilocus association testing for whole genome association studies using localized haplotype clustering. Genet Epidemiol. 2007;31(5):365-375.

82. Zhao J, Jin L, Xiong M. Nonlinear tests for genomewide association studies. Genetics. 2006;174(3):1529-1538.

83. Rutter M, Moffitt TE, Caspi A. Gene-environment interplay and psychopathology: multiple varieties but real effects. J Child Psychol Psychiatry. 2006;47(3-4):226-261.

84. Le Marchand L, Wilkens LR. Design considerations for genomic association studies: importance of gene-environment interactions. Cancer Epidemiol Biomarkers Prev. 2008;17(2):263-267.

85. Chapman J, Clayton D. Detecting association using epistatic information. Genet Epidemiol. 2007;31(8):894-909. 
86. Hunter DJ. Gene-environment interactions in human diseases. Nat Rev Genet. 2005;6(4):287-298.

87. Thomas DC, Witte JS, Greenland S. Dissecting effects of complex mixtures: who's afraid of informative priors? Epidemiology. 2007;18(2):186-190.

88. Kleeberger SR, Peden D. Gene-environment interactions in asthma and other respiratory diseases. Annu Rev Med. 2005;56:383-400.

89. O'Rahilly S, Barroso I, Wareham NJ. Genetic factors in type 2 diabetes: the end of the beginning? Science. 2005;307(5708):370-373.

90. Tang ZH, Xiao P, Lei SF, et al. A bivariate whole-genome linkage scan suggests several shared genomic regions for obesity and osteoporosis. $J$ Clin Endocrinol Metab. 2007;92(7):2751-2757.
91. Ng SB, Buckingham KJ, Lee C, et al. Exome sequencing identifies the cause of a mendelian disorder. Nat Genet. 2010;42(1):30-35.

92. Ng SB, Turner EH, Robertson PD, et al. Targeted capture and massively parallel sequencing of 12 human exomes. Nature. 2009;461(7261):272-276.

93. Canani LH, Capp C, Ng DP, et al. The fatty acid-binding protein-2 A54T polymorphism is associated with renal disease in patients with type 2 diabetes. Diabetes. 2005;54(11):3326-3330. 